\title{
A STUDY ON INFLUENCES OF LIGHTING ON RESOURCE USAGE IN AN INSTITUTION LIBRARY
}

\author{
G. Thangaraj ${ }^{1}$, S. Suresh Balaji ${ }^{2}$ \\ ${ }^{l}$ Industrial Safety Engineering, Department of Mechanical Engineering, Knowledge Institute of Technology, Salem, \\ Tamilnadu \\ ${ }^{2}$ Assistant Professor, Department of Mechanical Engineering, Knowledge Institute of Technology, Salem, Tamilnadu
}

\begin{abstract}
Library is the place which provides resources for knowledge; those resources are books and sometimes e-libraries. The efficient usage of those resources requires proper reading environment which provides comfort and environmental aspects required for undisturbed reading. But the reading environment can be easily affected by environmental factors such as light, noise etc. in the study the lighting factor is considered and how it influences readers in using resources is studied. Questionnaire has been used to collect the details regarding resource usage in a library as a quantitative measure and lux meter has been used to measure light intensity inside and outside of library environment as a qualitative measure.
\end{abstract}

Keywords: Lighting, Library, resource usage.

\section{INTRODUCTION}

Lighting can be made possible by natural and artificial means, using the daylight efficiently is recommended by OSHAS to perform the task easily, effectively and also economically. Artificial lighting has to be made possible whenever the nature lighting is not sufficient for using the library, more often artificial lighting is provided after evening and also during moody days in raining seasons.

\subsection{Statement of the Problem}

In most of the institution's lighting has been made just for the sake of having it, due to economical and structural constrains. But in a reading environment the amount of light provided can easily affect the library users from using the library resources effectively.

\subsection{Purpose of the Study}

The purpose of this study is to investigate the lighting in a library and to determine that how the lighting in library influences the resource usage.

\subsection{Aim}

To know how lighting affects the user from using the library resources effectively

The main hypotheses are:

1) the lighting provided in library is quantitative and qualitatively sufficient for using library resources

2) the lighting affects the resource usage in the library

\subsection{Limitation and Delimitation}

Natural lighting cannot be obstructed completely for finding quality of artificial lighting provided due to continuous library usage by students and staffs, which keep doors and windows, open for ventilation.

Lux meter used to measure the illumination level at each respective reading and e-library desktops inclusive of both natural and artificial lighting values if provided during working hours.

\section{LITERATURE REVIEW}

\subsection{Lighting}

The average value for any library activities that involve visual task like reading and writing is about $500 \mathrm{~lx}$, which in a range between 300 and $750 \mathrm{~lx}$ [1].Reading, task involvement and productivity is largely affected by the amount of daylight. It shows that the effective use of daylight in an educational environment such as the library is important [2]. Daylight is variability because as the sun moves, the direction and the amount of daylight enter into the space through the window or roof vary [3].For activities that involve computers, occupant preferred light levels of $100300 \mathrm{~lx}$, while it increases to $300600 \mathrm{~lx}$ for occupants that spent less time on computers [4]. It is shown that for office spaces in Malaysia climate, if luminance falls below $500 \mathrm{~lx}[7]$, the supplementary lighting is required. While, a normal working environment will not required any artificial lighting at all if the space receive over 500 lux of illumination levels during all months [7]

\subsection{Lighting Disturbances}

Had found that most of the people chose to sit close to or within the sun patch, although some arranged their desk back to the window and not having a direct outdoor view [5]. There are three parts of daylight transmitted through 
windows which are diffuse light, direct transmitted light and redirected transmitted light [1]

\subsection{Influence of Lighting}

The elementary students in the classrooms with the most daylight improve in learning rates compared to students in the classroom with the least daylight by 21 percent[7].This result which have important implications for school design, affirm that daylight has a positive and significant influence on student performance [7]From the finding of the research, $56 \%$ of the users choose to seat near the window, and they remain in one place when study [2].The users satisfaction towards the library will affect the length of stay in the library, more preferable seat, and they will be able to focus on their activities in one place [2] One of the main factors that affect comfort of users is a good lighting and a comfortable chair [2]It was also found that the library users' comments such as "Daylight is often a factor in a seat choice, But I do not prefer direct sunlight from a window “ or "The amount of time spent in the library is mostly related to the amount I need to study, but the amount of daylight can also be a factor may affecting my length of stay " [2]

\section{METHODOLOGY}

Research method of the study is of both quantitative and qualitative. An institution library from south India is chosen as a case study. The data analysis is performed by providing questionnaires to library users and using their replies for quantitative analysis. As a qualitative measure the light intensity reading is taken at various reading zones of library, and also daylight about a meter outside the doors and windows is noted for analysis.

\subsection{Data Collection Procedure}

\subsubsection{Quantitative Data Collection}

Questionnaires are provided to the library users and asked to evaluate the question on the scale provided, the scale used here is strongly disagree to strongly agree on lighting comfort and lighting disturbances. In the mean time the duration of effective resource usage is noted. The data is collected in the morning, afternoon and evening of a sunny day.

\subsubsection{Qualitative Data Collection}

The light intensity reading is taken using lux meter during morning, afternoon and evening period of a day, it is taken in outside environment from where the light enters the library environment, it is also measured in the zones of academic reading, newspaper reading and e-library.

\subsection{Data Analysis}

The questioners replies are evaluated and calculated to get the average values, the readings from the lux meter were compared with the lighting standards needed in a reading environment. From the analysis of the data and its cross checking the resources usage of library with respect to lighting can be determined

\subsection{The Scale and Location of Study}

The study location chosen was an institution from south India, and the number of total seating provided are 98 , which can be spited in to 3 sections, as academic reading section(44),newspaper reading section(40) and e-library section(14), the structure of library seating and source of lighting are shown in the fig

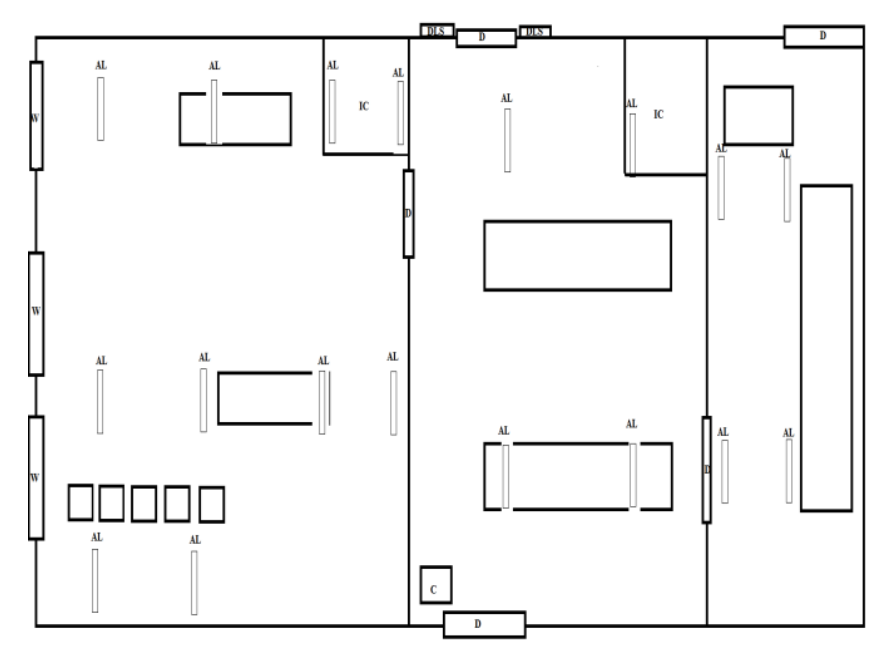

$\mathrm{W}=$ window, $\mathrm{D}=$ door, $\mathrm{C}=$ counter, $\mathrm{DLS}=$ diffused light source, $\mathrm{AL}=$ artificial lighting, $\mathrm{IC}=$ in charge cabin

\section{DATA ANALYSIS AND FINDING}

\subsection{Observation}

From the observation, the users are monitored for their undisturbed usage of library resource, the external noise was avoided for effectiveness of observation, The observation was taken place in three different times in a day, which is from 10.00 am to $11.00 \mathrm{pm}$ (47 respondents), $12.30 \mathrm{pm}$ to $1.30 \mathrm{pm}$ (62 Respondents), and $3.00 \mathrm{pm}$ to $4.00 \mathrm{pm}$ (57 respondents). the users were noted for effective usage of library, The observations shows that the lighting influence the effective resource usage in library this shows the users who received optimal level of lighting used the library resources better, from 10-11.00 AM the users resource usage is better all over, from 12.30-1.30 PM the user near to the sources of natural light used the resources better, and at 3-4 the resource usage has been varying.

\subsection{Questionnaire}

\subsubsection{Lighting}

\subsubsection{Lighting Affects Seating Preference}

From the questionnaire, it was found that lighting affects the seating preference of the users.32\% of the respondents agreed that lighting affects their seating preference and $29 \%$ of them strongly agreed with it. Therefore, it was more than half of the respondents, where $61 \%$ of them agreed that their seating preference affected by the lighting. 


\subsubsection{Lighting Affects Amount of Time Spent in}

\section{Library}

There were $32 \%$ of the respondents neither disagree nor agree with the statement that daylight affects. The amounts of the time spend in the library. While there were $37 \%$ of the respondent disagree that Lighting affects the amount of the time spend in the library. Thus, the amount of time spend in the library was not affected by the daylight since $69 \%$ of users go with it.

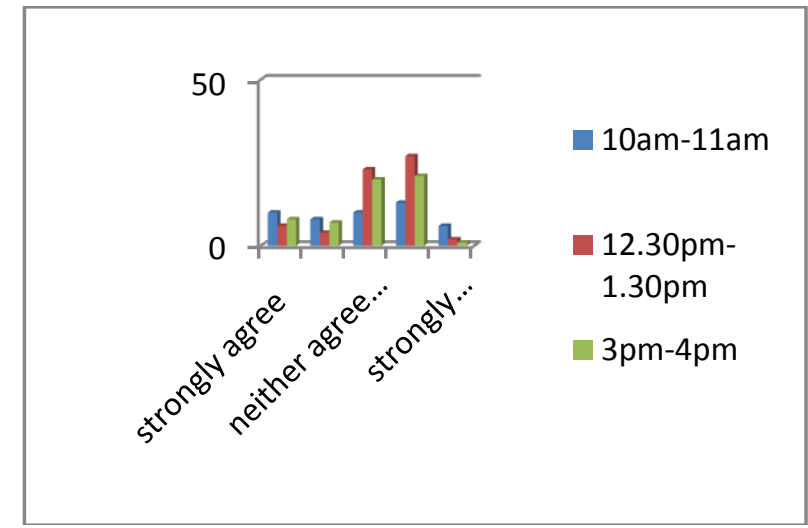

\subsubsection{Design of the Seating Layout of the Library}

\section{Optimizes Daylight}

In this $10 \%$ of the respondents neither disagree nor agree, but $65 \%$ of the respondents choose agree and strongly agree with it, thus the design of layout of seating with optimized light source is accepted

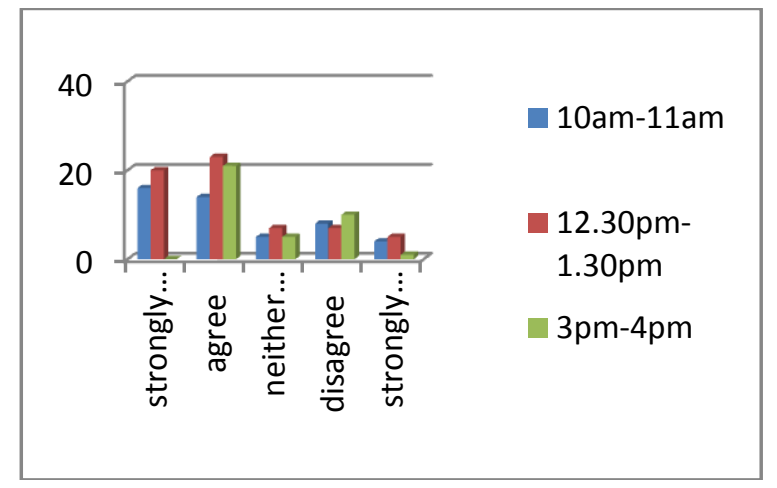

\subsubsection{Lighting Factors and Comfortness}

\subsubsection{Lighting Availability at the Work Place:}

\section{Adequacy}

In term of lighting availability (adequacy), from the average of the responds at 3 different timing goes with average

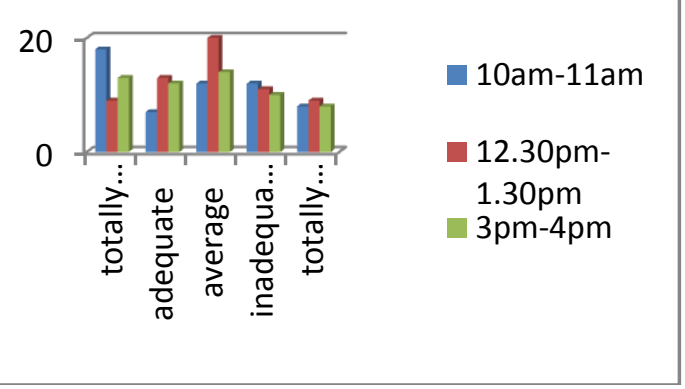

\subsubsection{Lighting Availability At The Work Place:}

\section{Brightness}

In terms brightness the percentage of people agreeing with brightness increases as the day goes on

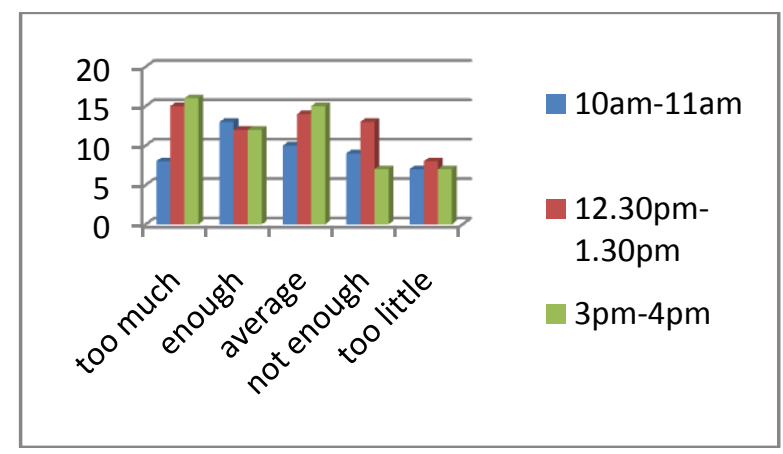

\subsubsection{Glare through Windows}

In terms of glare it is found to be higher in the 3-4 PM duration, it has been found both by natural and artificial lighting

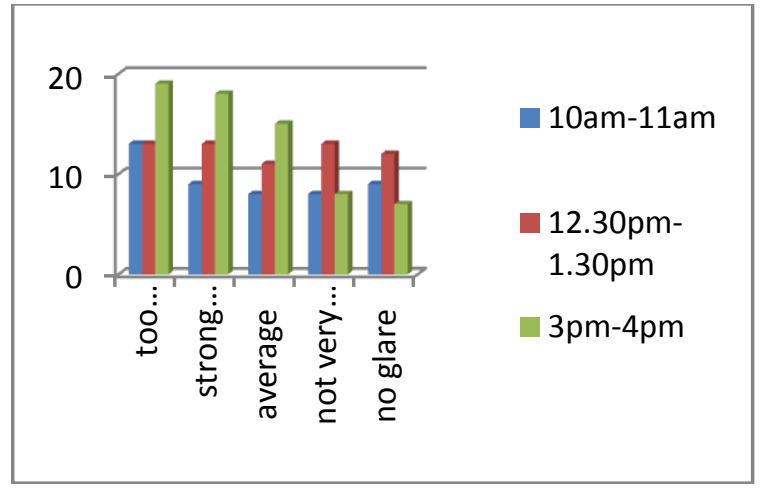

\subsection{Qualitative Analysis of Reading}

The light intensity readings are taken at all three different time periods, comparing that light intensity reading with the standards taken from journals. The average value for any library activities that involve visual task like reading and writing is about $500 \mathrm{~lx}$, which in a range between 300 and $750 l x$ [1]. The reading tasks performed here were made in to two compartments, the readings taken at the academic reading zones with respect to the 10-11am, 12.30-1.30 PM and 3-4 PM times shows.280, 370 and 170 lux and at newspaper reading zone it is 350,260 and 220 lux, this 
shows the lighting gets dropped during evening periods, that's not only due to setting of sun, it is also due to the influence of shades of building.

In the e-library zone we took the standards as 100-300lux because for activities that involve computers, occupant preferred light levels of 100 to 300 lux, while it increases to 300 to $600 l x$ for occupants that spent less time on computers [4]. The light intensity reading taken with respect to that the mean of the reading taken desktop levels of 10$11 \mathrm{am}, 12.30-1.30 \mathrm{pm}$ and $3-4 \mathrm{pm}$ time periods are 80,84 , and 82 respectively. Which is little lesser than the minimum requirements. This is due to no direct source of natural lighting, and only diffused light source and artificial light sources are possible.

\section{CONCLUSIONS}

Lighting does influence the resource usage by students in an institution library; it also proved the hypothesis 2, where "the lighting influence the resource usage in the library" but the time spent in the library is not affected.65\% of users agrees with the optimized lighting in the library. The adequacy of lighting in the reading zone is average and the factors of brightness and glare are common during the evening. The lux level in the newspaper zones are optimum hence the newspaper resource are used more effectively during morning sessions, and the e-library zone is out of glare and brightness on screen in morning session but in the evening glare appears due to change in sun light and brightness on screen due to artificial lighting that decreases resource usage of e-library during evening session, the academic reading zone is less illuminated that does not allow the users to spent their time long enough to use resources effectively. As a short term measure for this, provide diffuser over artificial light sources, use blinds or drapes on direct light sources, and as a long term measure use indirect or shield lighting to avoid intense or uneven lighting, and also re-orient the work station for better angle of lighting.

\section{REFERENCES}

[1]. Carla Balocco, R. C. (2008). Natural light design for an ancient building: A case study. Journal of Cultural Heritage, 9, 172-178.

[2]. Hasirci, D. K. K. (2011). Daylighting Concepts for University Libraries and Their Influences on Users' Satisfaction. The Journal of

Academic Librarianship, 37(6), 471479

[3]. Dean, E. T. (2005). Daylighting Design in Libraries (pp. 3-23). Libris Design Project.

[4]. Fontoynont, M. \& Escuyer, S. (2001). Lighting controls: A Lighting Research and

Technology, 33(2).

[5]. Wang, N. \& Boubekri, M. (2010). Design recommendations based on cognitive, mood and preference assessments in a sunlit

workspace. Lighting Research and Technology, 43(1), 5572.
[6]. Heschong-Mahone Group (2003). Windows and classrooms: A study of student performance and the indoor environment.Technical report P500-03-082-A-7. Fair Oaks, CA: Heschong- Mahone Group.

[7]. A. Zain-Ahmed, Sopian, K., Othman, M.Y.H., Sayigh, A.A.M. \& Surendran, P. N. (2002). Daylighting as a passive solar design strategy in tropical buildings: A case study of Malaysia. Energy Conversion and Management, 43, 17251736. 